\title{
START Reading Comprehension Skills for Undergraduate Students: An Empirical Study
}

\author{
Hiyam Al-Badareen ${ }^{1, *}$, Dina Al-Jamal ${ }^{2}$, Fawwaz Al-Abed AL-Haq ${ }^{3}$ \\ ${ }^{1}$ Language Centre, Al al-Bayt University, Jordan \\ ${ }^{2}$ Department of Curriculum and Instruction, Yarmouk University, Jordan \\ ${ }^{3}$ Department of English Language and Literature, Yarmouk University, Jordan
}

Received August 11, 2020; Revised October 8, 2020; Accepted October 19, 2020

\section{Cite This Paper in the following Citation Styles}

(a): [1] Hiyam Al-Badareen, Dina Al-Jamal, Fawwaz Al-Abed AL-Haq, "START Reading Comprehension Skills for Undergraduate Students: An Empirical Study," Universal Journal of Educational Research, Vol. 8, No. 12, pp. 6988 6997, 2020. DOI: 10.13189/ujer.2020.081266.

(b): Hiyam Al-Badareen, Dina Al-Jamal, Fawwaz Al-Abed AL-Haq (2020). START Reading Comprehension Skills for Undergraduate Students: An Empirical Study. Universal Journal of Educational Research, 8(12), 6988 - 6997. DOI: 10.13189/ujer.2020.081266.

Copyright $\bigcirc 2020$ by authors, all rights reserved. Authors agree that this article remains permanently open access under the terms of the Creative Commons Attribution License 4.0 International License

\begin{abstract}
This study aimed to scrutinize the effect of the Students and Teachers Actively Reading Test (START) framework on $\mathrm{Al}$ al-Bayt undergraduate students' reading comprehension. The study pursued a quasi-experimental design that involved two cohorts: intervention and control. The intervention cohort included 33 students and the control cohort contained 34 students. These students came from various backgrounds and reading levels but were all enrolled in English (101) during the $2^{\text {nd }}$ term of the 2019-2020 school year. To collect data, the researchers developed both an educational program depending on the START framework and a pre-posttest. The tools were presented to a jury of 10 referees to prove their validity. They were also piloted to prove their stability. The instructional program encouraged the teacher to use scaffolding techniques and reading strategies to instruct the students. Data were extracted according to the statistical packages program (SPSS). Based on the statistical analysis, the pre-posttest showed significant discrepancies among the participants of the two groups. The learners in the intervention group showed better performance than those of the control one. Therefore, the START framework helped learners interact with the reading text and it enhanced students' achievements in reading comprehension.
\end{abstract}

Keywords Reading Comprehension, The START Framework, Reading Strategies, Undergraduate Students

\section{Introduction}

Reading is a basic linguistic skill that helps people communicate and gain knowledge. Thus, a language cannot be learned without knowing how to read and comprehend in that language. Fundamentally, many researchers tackled the issue of reading. Bhatti (2016) defined reading as grasping the meaning of written words implying comprehension, recognition, fluency, and interest. He maintained that reading comprehension determines how readers interact with a text by using their prior knowledge to add meaning to the words.

Ceran (2015) and Pearson and Cervetti (2017) stated that reading not only involves uttering sounds or words, but also means comprehending the emotions, ideas, and messages included in a text. Basically, reading and comprehension are always connected (Pearson and Cervetti, 2017). It can be inferred that reading is to decode words, phrases, and sentences to get the meaning of what is being read.

Because reading and comprehension are intertwined, teaching or learning reading in English as a Foreign Language (EFL) classrooms proves a difficult task. As such, Othman, Mahamud, and Jaidi (2014) viewed reading comprehension as the point when readers can judge the information they read, connect what they read with what they already know, and make decisions drawing on what they read. Hence, readers need to learn strategies to comprehend a text and be strategic readers (Othman et al., 
2014)

Scharlach (2008) highlighted that students should be taught reading strategies that lead to engagement and interaction with a text. Accordingly, she created the Students and Teachers Actively Reading Text (START) framework to help students develop and improve their comprehension through modeling and scaffolding strategies. START consists of three stages: before reading, during reading, and after reading. Each stage contains specific techniques including predicting, visualizing, making connections, questioning, determining the main idea, summarizing, checking predictions, and making judgments.

Considering the Jordanian context, English is taught as a foreign language, so students are rarely exposed to English or practice English. In most cases, EFL teachers face students who read at different levels. Smadi and Alshra'ah (2015) maintained that reading in a foreign language is more difficult than reading in a native language since students have fewer opportunities to read or communicate in that foreign language. So, teachers need to seek new methods of instruction to help their students achieve success (Smadi and Alshra'ah, 2015). Thus, teachers require support and scaffolding strategies to help them enhance each learner's reading performance.

This study investigates the START framework's effect as a scaffolding strategy on the Jordanian undergraduate students' reading comprehension to help them develop their reading performance. Aslam, Khanam, Fatima, Akbar, and Muhammad (2017), emphasized the significance of applying scaffolding strategies among university students where it is more challenging than applying them at grade schools. They added that teachers often use scaffolding instruction styles in grade school classes but they style is less common in university classes. The present study, therefore, targeted the Jordanian undergraduate students to examine the START framework's impact on their reading comprehension.

\subsection{Statement of the Problem}

Throughout their teaching English as a foreign language in Jordan, the researchers noticed that students lack the ability to understand or show interest in what they read. This is due to the conventional methods followed in the EFL classrooms where teachers ask students to read the text and then answer questions that follow. Besides, it was noticed that there is no focus on teaching reading comprehension strategies in the EFL classrooms. As Al-Jamal, Al-Hawamleh, and Al-Jamal (2013) indicated, EFL teachers focus on reading assessment by asking questions instead of directing their classes through strategic instruction. Students have difficulty applying reading strategies such as interpreting, questioning, making judgments, and likewise (Staudinger, 2017). Accordingly, the researchers aimed to find a strategy to enhance the university students' reading comprehension levels. They chose the START framework with the intent of developing students' understanding and interest in reading.

\subsection{Purpose of the Study}

The current study aimed at inspecting the effect of the START framework on the reading comprehension of the Jordanian EFL students at Al al-Bayt University. This aim is supported by Aslam, et al. (2017), who stressed that it is essential to apply reading strategies among undergraduate students where it is more challenging than applying the same strategies at grade schools.

\subsection{Research Question}

In order to fulfill the intent of the study, the researchers formulated the following research question:

Are there any statistically significant differences at $(a=$ 0.05 ) between the mean scores of the intervention group and those of the control group on the reading comprehension post-test that may be attributed to the instructional method (viz. START-based instruction vs. conventional instruction)?

\subsection{Significance of the Study}

The current study is purposeful as it helps EFL students improve their reading skills to master the language and have the aptness to communicate, interact, and express themselves. Based on this perspective, the conclusions related to the START framework's efficacy can be beneficial for EFL developers of curriculum, instructors, and students. As for the EFL developers, this study can provide them with a framework that includes reading strategies integrated into the teachers' and students' textbooks taught in English classrooms. EFL instructors can benefit from this study in designing their courses' reading syllabus based on the current study's instructional program. In terms of learners, they may benefit from this study to expand their reading abilities by following the framework's techniques in the instructional program.

\subsection{Definitions of Terms}

START: In relevance to Scharlach (2008), an instructional framework is planned to help students develop and improve their comprehension. It consists of three stages (before, during, and after reading). Each stage contains specific strategies including predicting, visualizing, making connections, questioning, determining the main idea, summarizing, checking prediction, and making judgments. This framework was adopted in the present study to be used as an instrument for teaching reading comprehension.

Predicting: in this study, predicting means guessing of 
what the readers are going to read about in the text by looking at the title, subtitles, pictures, and the like.

Visualizing: it means to draw mental pictures about what is happening in the text.

Making connections: in relevance to this study, making connections refers to linking what the readers know with what they read.

Questioning: in this study, questioning means the students' ability to ask themselves questions concerning the text's subject matter to show interactivity with the text.

Identifying the main idea: this strategy relates to determining critical information by selecting the most important idea or ideas.

Summarizing: it refers to the students' capability to write briefly about the significant thoughts embodied in the text using their own words.

Checking predictions: in this study, checking predictions is the students' ability to reconsider their original predictions and check if they are either confirmed or not confirmed after reading the text.

Making judgments: it refers to the students' ability to judge the text after reading expressing their opinions and feelings towards the text.

Comprehension Instructional Framework: According to Liang and Dole (2006), various thoughts and premises outline the teacher's instruction. For the current study, comprehension instructional framework means reading strategies organized through stages that teachers could follow in reading comprehension.

\section{Literature Review}

\subsection{EFL Reading Comprehension}

The significance of reading in a person's life has been ascertained by many educational researchers indicating that it is a crucial skill that has an important influence on the educational, occupational, enjoyable, and social aspects of life (Paris and Jacobs,1984; Freahat and Al-Faoury, 2014; Qarqez and Abu Rashid, 2017; Radaideh, Al-Jamal, and Sa'di, 2020). Reading in a foreign language has been emphasized, pointing out difficulties and strategies that can be addressed to face these difficulties.

Alyousef (2006), for example, described how to teach reading comprehension for EFL learners. He discussed various methods and strategies that EFL teachers could draw on in a reading class. He concluded that EFL teachers should focus on intensive reading to encourage motivation and understanding. This is because intensive reading includes predicting, visualizing, questioning, and likewise that students can apply to expand their comprehension.

Al-Jarrah and Ismail (2018) examined the reading strategies already utilized by undergraduate learners who studied English as a foreign language. They interviewed ten EFL students at Universiti Sultan ZainalAbidin and
Universiti Malaysia Terengganu and found that the students used linguistic, formal, cultural, and content schema to aid in reading difficulties. The students also used translation from Google, dictionaries, and books on grammar. It was recommended that EFL instructors, planners, pedagogical scholars, and learners cooperate to find the appropriate strategies to improve their reading performance.

\subsection{Comprehension Instructional Frameworks}

Liang and Dole (2006) described five reading instructional frameworks to help stakeholders such as teachers, education planners, and policymakers understand and use them to plan and teach reading. They chose the frameworks carefully based on specific criteria. The first criterion was the framework's research base; that is, the framework as a whole was used in research, not only parts of it. The second criterion was the balance in which they selected half of the frameworks focusing on the content and the other half focusing on the strategy instruction. The last was looking for the frameworks that were less common among educators.

Consequently, Liang and Dole (2006) selected the frameworks of the Scaffolded Reading Experience (SRE), Questioning the Author (QtA), Collaborative Strategic Reading (CSR), Peer-Assisted Learning Strategies (PALS), and Concept-Oriented Reading Instruction (CORI). The SRE and QtA frameworks concentrate on comprehending the text's content and are not considered with teaching reading strategies. On the contrary, CSR and PALS concentrate on teaching reading strategies without focusing on the text's content. The fifth framework, CORI, combines both understanding the content and teaching the strategies.

The researchers described the frameworks in terms of particular characteristics like the core of teaching, grouping type, scaffolding, instructor planning, the time needed to complete a teaching unit, and text types needed for instruction. For example, in the SRE and QtA frameworks, the teachers need to be highly prepared and plan their lessons. The teaching unit does not take a long time, just a few days or one to two weeks, depending on the text with varied daily lessons, and students can be divided into whole or small groups. In the CSR and PALS frameworks, teachers need to introduce and model the strategies included in the frameworks though they do not need much time to plan the lessons because the authors provide them. Another point concerning these two frameworks is that teaching takes much time, nearly (semester to a year in CSR and 15 weeks in PALS). This is because teachers need to introduce, model, and scaffold the strategies and repeat these procedures until they practice them independently, and the teacher's role turns to monitor the students' performance.

As for the fifth framework, CORI, it is similar to the SRE and QtA in that it requires the teacher to be highly 
prepared and involved in teaching the framework to help students understand the text's content. It is also similar to CSR and PALS in that it focuses on modeling and scaffolding the strategies. Then students practice them independently. There are different forms of groups in the CORI framework, such as whole, small, or collaborative. The lessons are varied and teacher-generated, and they can last from weeks to months, depending on the topic of the text. In conclusion, the researchers indicated that they presented these frameworks to help teachers decide which to choose for teaching reading. They stated that they did not imply which one is better than the other, and the decision is left for the teachers based on their students' needs and pedagogical knowledge.

\subsection{Empirical Studies}

According to Scharlach (2008), teachers have difficulties in teaching reading comprehension strategies that help students become good readers due to the complexity of the strategies and many reading programs. She maintained that teaching comprehension needs to be improved, and there is an urgent need to build understandable models for teaching comprehension. She designed START (Students and Teachers Actively Reading Text) framework to enforce students' reading achievement depending on the fact that there are a few studies that tackle using multi strategies in teaching reading.

To achieve the study's purpose, 81 third grade students with five teachers were randomly selected and assigned to three groups: control, strategy-only (ST), and the START groups. In the control group, the instruction was handled by engaging students in the usual reading activities. In the Strategy-only and START groups, modeling and scaffolding metacognitive reading strategies led instruction, but students in the START group were trained to complete the ART (Actively Reading Text) comprehension self-monitoring recording sheets to help them develop their metacognitive knowledge. Before the study project, a pre-test was administered to students in the three groups to evaluate their reading comprehension levels. A post-test and a questionnaire were then administered at the end of the program to check students' reading comprehension

Based on the analyzed results, it was concluded that there was a statistically significant difference among the three groups between the pre-test and post-test gains in favor of the START group. As such, the START framework proved to be helpful and useful in developing students' comprehension. Besides, based on the questionnaire results, the students stated that they felt excited during applying the START strategies and were motivated and engaged in reading the text. Finally, teachers reported that START provided them with a framework to help them use metacognitive strategies in teaching reading.

Othman, Mahamud, and Jaidi (2014) scrutinized the effect of metacognitive strategy on students' understanding when reading expository texts. They based the theoretical framework for their study on the Students and Teachers Actively Reading Text (START) Reading Strategies Diagram in Scharlach (2008). They adapted and modified the START framework and applied metacognitive strategy through reading stages- before, during, and after reading. The strategies used under the metacognitive strategy umbrella included guessing, formulating questions, focusing on difficult words and looking up their meanings in dictionaries, linking the text with their knowledge, summarizing and assessing the reading material.

The study was implemented on 60 students who were chosen as research respondents. These students consisted of 32 male and 28 female students enrolled in a government school in Brunei Muara District. A quasi-experimental design was applied in which the students were distributed into two groups: experimental and control. The experimental group was taught based on the metacognitive strategy, while the control group was taught via the conventional teaching method. The tools included a pre-test, a post-test, and a questionnaire. The data were analyzed statistically using SPSS. Based on the results, the researchers concluded that the metacognitive strategy positively affects reading comprehension among students compared to the conventional way of teaching that did not use the metacognitive strategy.

In a similar study carried by Al Eissa and Al-Bargi (2017), the effectiveness of implementing scaffolding strategies in supporting reading comprehension skills was investigated. They adapted some strategies from the START framework, which are: questioning, visualizing, as well as making a connection. They added other scaffolding strategies such as activating prior knowledge and using graphic organizers. Like the START framework, they divided the reading text into three phases: pre, during, and post. The study sample consisted of thirty-three female students at King Abdulaziz University in Jeddah in Saudi Arabia. The researchers classified the students into two groups: control and experimental groups, and they used pre-test and post-test. Both groups were exposed to the same reading lessons, but the experimental group was exposed to scaffolding strategies. Furthermore, the researchers administered an open-ended questionnaire. The results showed a statistically significant difference between the pre-test and post-test of the experimental group in favor of the post-test. Moreover, students showed positive attitudes towards the scaffolding strategies.

Reviewing the related literature, it has been noticed that researchers in the field have proved how important and influential are the reading strategies in supporting and enhancing reading comprehension among learners. These studies have been conducted on different reading strategies with different contexts and samples of studies. Nonetheless, there is no experimental study - to the researchers' knowledge- conducted in the Jordanian context, 
particularly on university students, to examine the effect of scaffolding instructional frameworks on developing the students' reading performance. As a result, the researchers feel a need to bridge the gap and conduct a study using an instructional framework (i.e., START) with $\mathrm{Al}$ al-Bayt University undergraduate students hoping that it may help them achieve progress in their reading comprehension.

\section{Method}

\subsection{Design}

This study pursued a quasi-experimental design. The participants were allocated into two cohorts, one cohort was addressed randomly as an experimental group, and the other was a control. They were investigated to check the study variables' effectiveness: the dependent, reading comprehension, and the independent that was the instructional method based on the START framework with its eight reading comprehension strategies.

\subsection{Participants}

The study participants included the undergraduate students of Al al-Bayt University who studied the English language as a compulsory university requirement during the $2^{\text {nd }}$ semester of 2019/2020. They were chosen conveniently as the researcher is an English instructor at $\mathrm{Al}$ al-Bayt University. The participants were sixty-seven first-year students university students distributed to two classes of English (101). The students of these classes were of various specializations and background knowledge. Their level of English language is intermediate as they studied English at schools for 12 years. Besides, the classes consisted of both male and female students. The participants were divided randomly into experimental and control groups, and both cohorts were exposed to pre-post test to examine their level of reading comprehension skills. The experimental cohort was trained on the START framework strategies while the control was not subjected to the intervention.

\subsection{Instrument}

The researchers developed a pre-posttest that included 24 multiple-choice questions to collect data relevant to the study's aim. It covered the START framework's reading strategies, namely: predicting, visualizing, making connections, questioning, determining the main idea, summarizing, checking prediction, and making judgments. The pre-posttest was intended to evaluate the students' reading skills before and after applying the research to check if there were any differences pertinent to the START framework's instructional method.

\subsection{Validity and Reliability of the Test}

To investigate the instruments' validity, the test and instructional program were submitted to a validation jury of ten expert professors of EFL. Their modifications and recommendations were taken into consideration. Moreover, the content validity was set up throughout the Table of specification (Table 1).

Table 1. Table of Specifications of the Reading Test

\begin{tabular}{|c|c|c|}
\hline $\begin{array}{l}\text { Reading } \\
\text { Strategy }\end{array}$ & $\begin{array}{l}\text { Number } \\
\text { of Items }\end{array}$ & Outcomes \\
\hline Predicting & 3 & $\begin{array}{l}\text { to be able to define the strategy as } \\
\text { well as think deeply and predict } \\
\text { about the text }\end{array}$ \\
\hline Visualizing & 3 & $\begin{array}{l}\text { to be able to determine the strategy } \\
\text { and visualize images of reading text } \\
\text { for better understanding }\end{array}$ \\
\hline $\begin{array}{l}\text { Making } \\
\text { connections }\end{array}$ & 3 & $\begin{array}{l}\text { to be able to distinguish the strategy } \\
\text { and make a connection between the } \\
\text { text and the real life of the learner }\end{array}$ \\
\hline Questioning & 3 & $\begin{array}{l}\text { to be able to recognize the strategy } \\
\text { think about the information between } \\
\text { the lines }\end{array}$ \\
\hline $\begin{array}{l}\text { Identifying } \\
\text { the Main Idea }\end{array}$ & 3 & $\begin{array}{l}\text { to be able to identify the strategy and } \\
\text { decide the main idea of the text }\end{array}$ \\
\hline Summarizing & 3 & $\begin{array}{l}\text { to be able to determine the strategy } \\
\text { and summarize a text in the learner's } \\
\text { own words }\end{array}$ \\
\hline $\begin{array}{l}\text { Checking } \\
\text { Prediction }\end{array}$ & 3 & $\begin{array}{l}\text { to be able to define the strategy and } \\
\text { check and make sure of the learners' } \\
\text { original prediction }\end{array}$ \\
\hline $\begin{array}{l}\text { Making } \\
\text { Judgments }\end{array}$ & 3 & $\begin{array}{c}\text { to be able to identify the strategy and } \\
\text { think creatively and make a } \\
\text { judgment on a text }\end{array}$ \\
\hline Total & 24 & \\
\hline
\end{tabular}

As for the pre-post test's reliability, the researchers conducted a pilot study including18 students who were not a part of the main study participants. Next, they tested the students, and after two weeks, they retested them. Then the Cronbach alpha coefficient was calculated to check the reliability of the test. Table 2 displays the test-retest values and Cronbach alpha coefficients for each test element and the entire test.

Table 2. Correlation Coefficients and Test-Retest Values of the Reading Test

\begin{tabular}{|c|c|c|}
\hline Strategy & $\begin{array}{c}\text { Correlation } \\
\text { Coefficient }\end{array}$ & Test-Retest Value \\
\hline Predicting & .79 & .75 \\
\hline Visualizing & .75 & .73 \\
\hline Making connections & .74 & .71 \\
\hline Questioning & .73 & .79 \\
\hline Identifying the main idea & .72 & .77 \\
\hline Summarizing & .77 & .75 \\
\hline Checking prediction & .82 & .80 \\
\hline Making judgments & .78 & .77 \\
\hline Reading Test & .79 & .78 \\
\hline
\end{tabular}


Table 2 manifests that the correlation coefficients of the START reading strategies (predicting, visualizing, making connections, questioning, identifying the main idea, summarizing, checking prediction, making judgments) and the whole test were $.79, .75, .74, .73, .72, .77, .82, .78$, and .79 respectively. The test-retest reliability values for predicting, visualizing, making connections, questioning, identifying main idea, summarizing, checking prediction, making judgments and the entire test were $.75, .73, .71, .79, .77, .75, .80, .77$, and .78 respectively. Consequently, the test proved to be a reliable of reading comprehension (Odeh, 2010).

\subsection{The Instructional Program}

To achieve the study's purpose, an instructional program based on the START framework was designed to teach the experimental group within a training period of eight weeks and two days involving 18 sessions where each session lasted for 60 minutes. The objectives of the instructional program were represented in helping the students to be able to apply all the strategies included in the START framework namely: predicting, visualizing, making connections, questioning, identifying main ideas, summarizing, checking prediction, and making judgments. The material was based on four units' reading activities from the textbook New Headway Plus- Intermediate Student's Book to implement the instructional program.

The instructional program was carried out following the next procedures:

- introducing the program telling the students about the START framework, its stages (before, during, and after), and the strategies it includes, namely: predicting, visualizing, making connections, questioning, determining the main idea, summarizing, checking prediction, and making judgments.

- introducing the strategies in the same order as they are in the START framework starting with the pre-reading (predicting), during (visualizing, making connections, questioning), and after reading strategies (identifying the main idea, summarizing, checking prediction, making judgment).

- teaching the reading texts included in the students' textbook focused on these strategies by explaining, modeling, and scaffolding these strategies

- after making sure they became familiar with the strategies. They were given a reading text and asked to apply the strategies independently.

\subsection{Teaching the Control Group}

The control group was taught in the conventional way following the guidelines in the teacher's book New Headway Plus - Intermediate. First, key vocabulary was introduced by asking students to guess meaning and explain words, then they were given feedback on the correct meaning. Second, students were asked to read the text and fill in the gap with missing words or phrases. Third, students were asked to read the text again and answer the comprehension questions. Finally, Students were asked to do exercises that require to find similar meanings of words or phrases in the text or match words and phrases with their meaning.

\section{Results}

To answer the research question: "Are there any statistically significant differences at $(\gamma=0.05)$ between the mean scores of the experimental group and those of the control group on the reading comprehension post-test that may be attributed to the instructional method (viz. START based instructional program vs. conventional instruction)?", means and standard deviations of students' performance in experimental and control groups were calculated. The results are shown in Table 3.

Table 3. Means and Standard Deviations of the Groups on Pre-posttest

\begin{tabular}{|c|c|c|c|c|c|}
\hline \multirow{2}{*}{ Group } & \multirow{2}{*}{ No. } & \multicolumn{2}{|c|}{ Pre- test } & \multicolumn{2}{c|}{ Post-test } \\
\cline { 3 - 6 } & & Mean & Std. Deviation & Mean & Std. Deviation \\
\hline Experimental & 33 & 7.727 & 3.024 & 20.455 & 1.970 \\
\hline Control & 34 & 8.147 & 2.630 & 13.765 & 2.618 \\
\hline
\end{tabular}

Table 3 demonstrates that there are differences between the two groups of the study due to the post-test scores. It shows that the START group students outperformed those in the control group as the mean score is 20.455 compared to 13.765 for the control group. This indicates that the START group showed improvement in their reading performance. To emphasize this result, a one-way analysis of covariance (ANCOVA) was employed to test the instructional method's significance effect. Table 4 illustrates the summary results of ANCOVA.

Table 4. Summary Results of One-way ANCOVA analysis

\begin{tabular}{|c|c|c|c|c|c|c|}
\hline Source & $\begin{array}{c}\text { Type III } \\
\text { Sum of } \\
\text { Squares }\end{array}$ & Df & $\begin{array}{c}\text { Mean } \\
\text { Square }\end{array}$ & F & Sig. & $\begin{array}{c}\text { Partial Eta } \\
\text { Squared }\end{array}$ \\
\hline Pre-test & 49.605 & 1 & 49.605 & 10.558 & .002 & .142 \\
\hline $\begin{array}{c}\text { Instruction } \\
\text { method }\end{array}$ & 716.654 & 1 & 716.654 & 152.533 & .000 & .704 \\
\hline Error & 300.694 & 64 & 4.698 & & & \\
\hline Total & 20599.000 & 67 & & & & \\
\hline
\end{tabular}

Table 4 shows that the instructional method's significant value in the combined reading strategies is $(\gamma=0.000)$, which is less than $(r=0.05)$. This means that START affected the students' performance in the combined reading comprehension strategies after excluding the pre-test scores in favor of the experimental group. It is also clear from Table 4 that the effect of the instructional method explained that $70.4 \%$ of the variance in the combined reading comprehension strategies.

Furthermore, adjusted means and standard errors of the 
combined reading comprehension strategies for experimental and control groups were extracted. The results are tabulated in Table 5.

Table 5. Adjusted and unadjusted group means and variability.

\begin{tabular}{|c|c|c|c|c|}
\hline \multirow{2}{*}{ Group } & \multicolumn{2}{|c|}{ Adjusted Means } & \multicolumn{2}{c|}{ Unadjusted Means } \\
\cline { 2 - 5 } & Mean & S.E & Mean & STD \\
\hline Experimental & 20.522 & .343 & 20.455 & 1.970 \\
\hline Control & 14.186 & .349 & 13.765 & 2.618 \\
\hline
\end{tabular}

*The maximum score for the combined reading comprehension strategies is 24 .

Table 5 shows that there are differences between the two groups after excluding the effect of the pre-test scores in favor of the experimental group. This is evident from the experimental group's adjusted mean score, which is 20.522 compared to 14.186 for the control group. This indicates that the START framework affected the students' reading performance positively.

In order to investigate which reading comprehension strategy students showed differences in their reading comprehension performance, one-way MANCOVA analysis was conducted to investigate the effects of the instructional method in the eight reading strategies. Table 6 illustrates the results.

Table 6 shows that the instructional method demonstrated a statistically significant difference due to the value of the significance $(r=0.000)$, which is less than $(x=0.05)$ in all the START reading strategies. This indicates that the instructional method affected the students' reading comprehension performance in each of the START strategies (predicting, visualizing, making connections, questioning, identifying the main idea, summarizing, checking prediction, and making judgments). To investigate this effect's size, partial eta squared values were extracted, as presented in Table 6 below. The most developed strategy was summarizing (0.558) followed directly by identifying the main idea (0.556), next came checking prediction and making judgments with the same effect value (0.459). The students showed development in making connections, visualizing, and predicting with effect values equal to $0.428,0.407$, and 0.333 , respectively. The least developed strategy was questioning (0.286).

Table 6. Results of One-way MANCOVA for START Reading Comprehension Strategies Posttest

\begin{tabular}{|c|c|c|c|c|c|c|c|}
\hline \multirow{2}{*}{ Source } & Reading strategies & $\begin{array}{c}\text { Type III Sum of } \\
\text { Squares }\end{array}$ & Df & Mean Square & F & $\begin{array}{c}\text { Sig. } \\
\text { Partial Eta } \\
\text { Squared }\end{array}$ \\
\hline \multirow{5}{*}{ Instructional method } & Predicting & 7.819 & 1 & 7.819 & 28.425 & .000 & .333 \\
\cline { 2 - 9 } & Visualizing & 7.724 & 1 & 7.724 & 39.142 & .000 & .407 \\
\cline { 2 - 9 } & Making connections & 7.590 & 1 & 7.590 & 42.697 & .000 & .428 \\
\cline { 2 - 9 } & Questioning & 4.602 & 1 & 4.602 & 22.835 & .000 & .286 \\
\cline { 2 - 9 } & Identifying the Main Idea & 14.344 & 1 & 14.344 & 71.370 & .000 & .556 \\
\cline { 2 - 9 } & Summarizing & 12.417 & 1 & 12.417 & 71.957 & .000 & .558 \\
\cline { 2 - 9 } & Checking Prediction & 9.458 & 1 & 9.458 & 48.272 & .000 & .459 \\
\cline { 2 - 9 } & Making Judgments & 5.735 & 1 & 5.735 & 48.388 & .000 & .459 \\
\hline
\end{tabular}




\section{Discussion}

According to Scharlach (2008), the START framework strategies include metacognitive strategies applied through modeling and scaffolding during the three reading (before, during, and after) stages. This study assumed that the START framework helps students build metacognitive comprehension in their English reading. For clarification, metacognition means thinking beyond thinking. McCune and Alexander (2007) defined metacognition as "the process of thinking about and monitoring one's thinking. It refers to a person's awareness of reflection on, understanding of, and control over their mental operations" (p. 96). McCune and Alexander (2007) also stated that good readers are skillful in utilizing metacognitive strategies. However, they ascertained that poor readers could be taught these strategies by explicitly explaining, modeling, scaffolding, and applying them independently.

In the present study, START reading strategies were taught following the above-mentioned techniques (viz. explaining, modeling, scaffolding, and applying them independently). The results showed significant differences between the START and control groups in favor of the group which received the treatment based on the START framework. The intervention group students performed well using the reading strategies: predicting, visualizing, making connections, questioning, identifying the main idea, summarizing, checking prediction, making judgments. Scharlach (2008) concluded that the framework helped students promote their reading achievement and reinforce their use of metacognitive strategies. The results of the current study agree with Scharlach's conclusion.

Before commencing the process of teaching the START framework together with its eight strategies, it was thought that it would be overwhelming, especially with students whose majors were not English, and had little interest in learning English. Nevertheless, once the teaching process started, it was found that it was not difficult as the strategies can be applied to one text following a specific order, as mentioned earlier in this study. Besides, the students showed interaction and positive responses during the teaching process and effective engagement in text reading. For instance, after several classes where START strategies were explained and modeled by the teacher, students were given an extract from a reading passage entitled "The man who planted trees" from their textbook, and were asked to practice the strategies they have learned. They started with the pre-reading strategy of predicting. The teacher scaffolded the students by asking a set of questions as outlined below:

- (Teacher): Why are trees good for the environment? (Students): Trees are good because they are important for absorbing carbon dioxide and providing a source of food.

- (Teacher): So, what happens if trees are cut down?

(Students): The natural balance is disturbed
- (Teacher): When did the two World Wars take place? (Students): (1914-1918) and (1939-1945)

Then the teacher asked the students to look at the title and pictures and try to predict what the text is about.

(Students): a story about a man who fought in wars and another man planted the trees

The teacher asked these questions to activate the students' prior knowledge and help them follow the story. As Banditvilai (2020) pointed out, readers can predict what the text is about by activating their prior knowledge and looking at the title and the pictures. She added that this strategy makes students feel engaged and interacted with the text, leading to reading.

Next, the teacher asked the students to employ during reading strategies (visualizing, making connections, and questioning) followed by the after reading strategies (identifying the main idea, summarizing, checking prediction, and making judgments). The teacher taught these strategies by asking prompting questions as well as explaining difficult words. Eventually, the students were able to apply these strategies independently.

Looking at the results again, it is apparent that the students demonstrated remarkable differences in the above-mentioned sub-skills of the START framework. The students in the intervention group outperformed their counterparts in the control group. As is evident in Table 6, the students, for example, showed improvement in "summarizing," and it was the highest developed strategy due to the significant value of this strategy, $F(71.957)=p$ $=.000$, multivariate eta square $=.558$. The lowest developed strategy was "questioning," with a significance value of $F(22.835)=p=.000$, multivariate eta square $=.286$.

However, using any of the above reading strategies can indicate students' improvement in reading comprehension. As Boulware-Gooden, Carreker, Thornhill, and Joshi (2007) concluded, if the students employ one strategy (e.g. summarizing) comprehension will developed. They added that if the students use more than one strategy, comprehension is extensively developed.

To sum up, the START framework enhanced and improved the students' reading comprehension. This result aligns with Othman, Mahamud, and Jaidi (2014) in which they adapted and used some of START framework strategies and concluded that those strategies supported students in their reading performance to achieve a high level of reading comprehension. It also corresponds with Al-Jamal, et al. (2013), in which they emphasized the benefits of reading comprehension strategies in promoting and developing the students' reading performance. They also recommended that teachers should focus on teaching strategies such as predicting, making connections, identifying the main idea, summarizing, and likewise in their EFL classrooms as such strategies help students become metacognitive readers. All three studies show that 
using teaching strategies, such as the START framework, can improve students' reading comprehension.

\section{Conclusions and Recommendations}

This study aimed to scrutinize the START framework's effect on the students' reading comprehension at Al al-Bayt University. It was found that the START framework motivated the students and affected their reading performance positively. The researcher noticed that the students were encouraged to apply the START strategies in their reading. At first, they did not have any idea about these strategies, but after introducing, modeling, and scaffolding them by the teacher, the students could apply them independently. This was obvious in their answers whenever the teacher asked the students to apply these strategies.

As Abu Qbeita and Baniabdelrahman (2019) put it, teaching reading comprehension through strategies helps students be better readers and acquire more knowledge about handling a reading text. A further conclusion is that START strategies helped students enjoy reading as these strategies required students to express their opinions and make connections between what they read and what they know in their real life. This was proven by Al Eissa and Al-Bargi (2017), in which they maintained that reading strategies make students look at reading as an exciting and enjoyable task and have positive attitudes toward reading.

Finally, it is recommended that further research is required to prove the results of the current study due to the fact the little research is done on the effectiveness of the START framework. Another recommendation is that further research is needed on more participants to generalize the results as the number of participants in the current study is small. Moreover, the final recommendation is that EFL teachers should consider teaching comprehension to focus on reading strategies because these strategies proved their role in enhancing reading comprehension.

\section{REFERENCES}

[1] Abu Qbeita, A. \& Baniabdelrahman, A. (2019). Metacognitive Reading Strategies Employed by Al-Hussein Bin Talal University Students in Jordan. Dirasat, Educational Sciences,46(1), 791-802.

[2] Ahmed, S. (2015). Second Language Reading and Instruction. TESOL \& Applied Linguistics, 15. (2), 42-44.

[3] Al Eissa, A. \& Al-Bargi, A. (2017). The Impact of Scaffolding Strategies in Enhancing Reading Comprehension Skills of University Students in a Saudi Context. International Journal of Linguistics, 9(5) 1-22.

[4] Al-Jamal, D., Al-Hawamleh, M., and Al-Jamal, G. (2013).
An assessment of reading comprehension practice in Jordan. Jordan Journal of Educational Science,.9(3), 335-344.

[5] Al-Jarrah, H. \& Ismail, N. S. (2018). Reading Comprehension Strategies among EFL Learners in Higher Learning Institutions. Arab World English Journal (AWEJ),9(2), 315- 328

[6] Alyousef, H.S. (2006). Teaching Reading Comprehension to ESL/EFL Learners. Journal of Language and Learning, 5(1), 63-73.

[7] Aslam, N., Khanam, A., Fatima, G., Akbar, H., and Muhammad, N. (2017). A study of the impact of Scaffold Instructions on the Learning Achievements of Post-Graduate Students. Journal of Arts and Social Sciences, 4(1).

[8] Banditvilai, C. (2020). The Effectiveness of Reading Strategies on Reading Comprehension. International Journal of Social Science and Humanity, 10(2), 46-50

[9] Bhatti, M. S. (2016). Teaching Reading Skills Through Comprehension at the BS level. The Global Journal of English Studies,2(2), 1-11.

[10] Boulware-Gooden, R., Carreker, S., Thornhill, A., Joshi, M. (2007). Instruction of Metacognitive Strategies Enhances Reading Comprehension and Vocabulary Achievement of Third-Grade Students. The Reading Teacher,61(1) 70-77.

[11] Ceran, D. (2015). Investigation of High School Students' Reading Comprehension levels According to Various Variables. Educational Research and Review, 10(11) 1524-1534.

[12] Frankel, K., Becker, B., Rowe, M., \& Pearson, D. (2016). From what is Reading? What is Literacy? Journal of Education, 196(3), 3-17.

[13] Freahat, N. M. \& Al-Faoury, O. H. (2014). Jordanian High School EFL Teachers' and University EFL Instructors' Perceptions of the Reading Comprehension Content in EFL Textbooks. Theory and Practice in Language Studies, 4(11), 2231-2242.

[14] Liang, L. A. \& Dole, J. A. (2006). Help with Teaching Reading Comprehension: Comprehension instructional frameworks. The Reading Teacher, 59(8), 742-753.

[15] McCune, S. L., \& Alexander, V. C. (2007). CliffsTestPrep ${ }^{\circledR}$ FTCE: Professional Education Test. Hoboken, NJ: Wiley Publishing, Inc.

[16] Odeh, S. (2010). Measurement and Evaluation in Instructional Process. Irbid: Dar Al-Amal.

[17] Othman, Y., Mahamud, Z. \& Jaidi, N. (2014). The Effects of Metacognitive Strategy in Reading Expository Text. International Education Studies,7(13), 102-111.

[18] Paris, S. G.\& Jacobs, J. E. (1984). The Benefits of Informed Instruction for Children's Reading Awareness and Comprehension Skills. Child Development, 55(6), 2083-2093

[19] Pearson, D. \& Cervetti, G. N. (2017). The Roots of Reading Comprehension Instruction. In Israel, S. E. \& Duffy, G. G. (eds.). Handbook of Research on Reading Comprehension ( $2^{\text {nd }}$ ed.). New York: The Guilford Press.

[20] Qarqez, M. \& Abu Rashid, R. (2017). Reading 
Comprehension Difficulties among EFL Learners: The Case of First and Second Year Students at Yarmouk University in Jordan. Arab World English Journal (AWEJ), 8 (3), 421-431.

[21] Radaideh, E., Al-Jamal, D., \& Sa'di, I. (2020). Digital Storytelling: Time to be Considered in Reading Comprehension. Universal Journal of Educational Research, 8(6), 2621-2633, DOI: 10.13189/ujer.2020.080645

[22] Safadi, E. \& Rabab'ah, G. (2012). The Effect of Scaffolding Instruction on Reading Comprehension Skills. International Journal of Language Studies,6(2), 1-38.
[23] Scharlach, T. D. (2008). START Comprehending: Students and Teachers Actively Reading Text. Reading Teacher,62(1), 20-31.

[24] Smadi, O. \& Alshra'ah, M.. (2015). The Effect of an Instructional Reading Program Based on the Successful Readers' Strategies on Jordanian EFL Eleventh Grade Students' Reading Comprehension. Journal of Education and Practice, 6(15), 76-87.

[25] Staudinger, A. (2017). Reading Deeply for Disciplinary Awareness and Political Judgment. Teaching and Learning Inquiry, 5(1), 1-16. 